\title{
ALGUNOS APORTES EN TORNO A LA ACCIÓN DECLARATIVA DE INCONSTITUCIONALIDAD Y A SU CARÁCTER PREVENTIVO.
}

\section{CONTRIBUTIONS REGARDING THE DECLARA- TIVE ACTION OF UNCONSTITUTIONALITY AND ITS PREVENTIVE NATURE}

ELCIRA MARÍA TORRES ALIAGA'

\section{RESUMEN:}

La acción declarativa de inconstitucional, como herramienta para asegurar la supremacía constitucional, es una vía procesal autónoma y de excepción, de trámite sumario o sumarísimo, que se perfila como el instrumento más eficaz para interpelar la actuación de los jueces a los fines de salvaguardar los valores, derechos y garantías que la Constitución Nacional consagra, cuando una norma legal provincial, municipal o administrativa pudiera reputarse contraria al orden constitucional. Siendo esta acción esencialmente declarativa y de carácter preventivo, la tutela judicial debe ser instada, por regla general, antes de producida la lesión a los derechos constitucionales que se invocan. Ella tiene por objeto el análisis de la adecuación constitucional de un acto normativo determinado, de alcance general, siendo su finalidad la consiguiente declaración de invalidez o inaplicabilidad de la norma irregular en el caso concreto y respecto de aquel cuyo derecho subjetivo o interés legítimo ha sido amenazado o afectado.

\begin{abstract}
The declarative action of unconstitutionality, as a tool to ensure constitutional supremacy, is an autonomous and exceptional path, of summary procedure, which is emerging as the most effective instrument to incite the intervention of judges in order to safeguard the values, rights and guarantees that the National Constitution establish, when a provincial, municipal or administrative law could be considered in violation to the constitutional order. Since this action is essentially declarative and of a preventive nature, legal protection must be urged, as a general rule, before the violation to the invoked constitutional rights occurs. Its purpose is to analyze the constitutional adequacy of a specific normative act of general scope and its goal is a subsequent declaration of invalidation or inapplicability of the irregular rule for an specific case and regarding the one person whose right or legitimate interest has been threatened or affected.
\end{abstract}

1 Abogada - UNC, Facultad de Derecho y Ciencias Sociales, Egresada año 1998; Traductora Pública de Francés - UNC, Facultad de Lenguas, Egresada año 1979; Especialista en Derecho Procesal Constitucional - UBP, egresada año 2012; Diplomada en Derecho Municipal - US21 - año 2006 ; Funcionaria Judicial en la Secretaría Contencioso Administrativa del TSJ de Córdoba, años 1999-2001 y en la Secretaría Electoral y de Competencia Originaria del TSJ de Córdoba, años 2001-2019, Jubilada desde el 01-02-2019; Último cargo desempeñado: Secretaria Letrada de Cámara; Docente invitada de la Carrera de Especialista en Derecho Procesal Constitucional - Cohortes 2012/2013 y 2015/2016 en Módulo V: Procesos Constitucionales: La acción declarativa de inconstitucionalidad. 
PALABRAS CLAVE: Acción declarativa de Inconstitucionalidad Constitución Nacional - Constitución de la Provincia de Córdoba control de constitucionalidad.

KEY WORDS: Declarative action of unconstitutionality - National Constitution - Constitution of the Province of Córdoba - constitutionality control.

\section{Introducción}

En Argentina, el control de constitucionalidad como aseguramiento del principio de supremacía constitucional es realizado por todos los jueces, cualquiera fuera su competencia o grado, quienes ejercen el control difuso, siempre en caso concreto y a instancia de parte interesada, ya sea en procesos ordinarios o en procesos constitucionales, esto es con regulación constitucional.

El acceso a la jurisdicción constitucional puede realizarse tanto por vía principal, como acción o recurso -por medio del amparo, el hábeas corpus, el hábeas data, la acción declarativa de certeza y la acción declarativa de inconstitucionalidad provincial- como por vía incidental, de excepción o defensa, en el seno de otra acción, tal el caso del recurso extraordinario federal, o bien de oficio, por el Juez, previo a la aplicación de una norma para la resolución de una controversia.

Al respecto, cabe advertir que, en razón de la forma federal de gobierno adoptada por la República Argentina, cada provincia tiene su Constitución y códigos procesales propios y cuenta con órganos judiciales organizados piramidalmente que se encargan de resolver las cuestiones constitucionales en el orden local.

La tarea del control constitucional es ejercida por todos los jueces de la Nación, y en cada Provincia por los jueces y tribunales inferiores, y en última instancia local por los Tribunales Superiores de provincia, respecto de las Constituciones Provinciales, siendo, en último término, la Corte Suprema de Justicia de la Nación la intérprete y salvaguarda final de la Constitución Nacional y de los valores, derechos y garantías en ella contenidos². Asimismo, tras la incorporación al bloque de constitucionalidad-consagrada por el art. 75 inc. 22 de la Constitución Nacional de 1994- de los tratados de derechos humanos ratificados a ese momento y de aquellos a los que les fuere -en lo sucesivo- atribuida tal jerarquía por el Congreso de la Nación con el voto de las dos terceras partes de los miembros de cada Cámara, debe entenderse que los derechos en ellos reconocidos son complementarios de los ya consagrados en el texto constitucional.

Esto supone una modificación trascendental en nuestro sistema de control constitucional toda vez que obliga a todos los jueces de la República a efectuar lo que se ha dado en llamar el control de convencionalidad, controlando la validez de las normas no sólo a la luz de la Constitución Nacional sino también de los tratados a ella incorporados con igual jerarquía y de la interpretación que sobre los mismos hagan los tribunales internacionales.

En la jurisprudencia de la Corte Suprema de Justicia de la Nación ha quedado establecido, sin embargo, “...Que no incumbe a los jueces, en el ejercicio regular de sus atribuciones, sustituirse a los otros poderes del Estado en las funciones que le son propias (Fallos: 270:168). Porque la misión más delicada de la justicia nacional es la de poder mantenerse 
dentro de la órbita de su jurisdicción, sin menoscabar las funciones que incumben a los otros poderes o jurisdicciones"3.

Ahora bien, cuando el ejercicio de esas funciones ha puesto la ley o el acto ejecutado en conflicto con la Constitución misma, cuando una ley o un acto del Poder Ejecutivo estén en conflicto con las disposiciones, derechos y garantías que la Constitución consagra, siempre surge un caso judicial, que puede ser llevado ante los tribunales por la parte agraviada ${ }^{4}$.

En 1967, la Corte Suprema de Justicia de la Nación, al pronunciarse en la causa "Ciriaco Colella c/ S.A. Fevre y Basset y/u otro"s, acerca de la inteligencia del art. 72 de la Constitución Nacional, reiteró unánimemente la jurisprudencia de ese Tribunal en el sentido que sus facultades jurisdiccionales no alcanzan, como principio, al examen del procedimiento adoptado en la formación y sanción de las leyes.

Hoy, en cambio, tras una lenta y vacilante evolución jurisprudencial, la doctrina mayoritaria entiende que nada escapa al referido control si de lo que se trata es de moderar el ejercicio del poder público a los fines de salvaguardar los valores, derechos y garantías que la Constitución Nacional consagra.

Ello así, toda vez que la división de poderes no sólo significa separación de funciones sino también control mutuo de su ejercicio, de lo que se deriva que no es posible hablar de supremacía de la Constitución si no hay control o si quien está encargado de controlar la legitimidad constitucional de los actos es el propio poder que los emite. Por ello, en la actualidad se considera que siempre resultan justiciables el examen de la competencia del órgano, la observancia del debido proceso y la razonabilidad de la decisión'.

En Argentina, esta facultad de contralor fue reglamentada por el Congreso de la Nación en el art. $2^{\circ}$ de la Ley 27 que dispuso que la Justicia Federal nunca procede de oficio, ejerciendo su jurisdicción solamente en los casos contenciosos en que es requerida a instancia de parte, quedando excluida la consideración de la constitucionalidad o no de normas y actos de los otros poderes cuya aplicación no haya dado lugar a un litigio contencioso.

Se puede intentar definir el "caso constitucional" como una controversia de hecho o de derecho, planteada por parte legitimada, por medio de una acción judicial, individual o colectiva, en contra de parte legitimada, respecto de un conflicto de intereses actual, en relación a materia justiciable, en que un tribunal competente, actuando como tribunal constitucional, debe expedirse a instancia de parte interesada, declarando la inconstitucionalidad manifiesta de una norma, su inaplicabilidad en el caso concreto o su adecuación al orden constitucional?

Ello implica necesariamente la existencia de un agravio o gravamen de entidad suficiente y subsistente, con afectación constitucional, en perjuicio del titular de un derecho subjetivo o interés legítimo -interés personal y directo- en transe de ser lesionado por la norma o acto reputado inconstitucional, no imputable al accionar de quien se dice afectado.

Se exige, asimismo, que en la causa medie petición de parte interesada, toda vez que sólo la pretensión ejercida por el agraviado ante el órgano jurisdiccional resulta susceptible de incitar la jurisdicción; no hay posibilidad de control sin pedido de parte y sin

3 CSJN - Fallos: 272:231.

4 ver disidencia Ministro Varela en fallo citado supra.

5 CSJN - Fallos: 268:352.

6 CSJN - Fallos: "Bussi c. Camara de Diputados de la Nación", de octubre de 2001, http://ar.vlex.com/vid/-40046512.

7 BIDART CAMPOS, Germán, Manual de Derecho Constitucional Argentino, Ediar, Buenos Aires, 1972, pág. 65 y ss.. 
causa judicial a través de la cual dicha petición sea ejercida.

Ello significa, igualmente, que el juez no puede conocer ni decidir más allá de lo propuesto por las partes del litigio en la demanda y su contestación, a riesgo de vulnerar el principio de congruencia y de afectar las garantías de debido proceso y defensa en juicio, tan celosamente resguardadas por los artículos 8 inciso 1 y 25 inciso 1 del Pacto de San José de Costa Rica ${ }^{8}$.

En definitiva, el ejercicio de la jurisdicción por un tribunal de justicia se manifiesta en una "causa" o "caso contencioso", no sólo para interpretar el derecho y aplicarlo cuando existen derechos controvertidos, o cuando se pretende la reparación de un daño ya producido, sino también -y aún sin existencia de lesión- cuando se pretende la interpretación de una norma cuyo texto no es lo suficientemente claro y genera incertidumbre?.

\section{Los orígenes de la acción declarativa de inconstitucionalidad - Su diferenciación de la acción declarativa de certeza: la incertidumbre de contenido constitucional}

\section{1.- La acción meramente declarativa}

En la tarea de delimitar el objeto del examen propuesto, es menester considerar que las acciones meramente declarativas, como su denominación lo indica, se distinguen de las acciones de condena -que tienden a la ejecución efectiva de una prestación- por una parte, y de las acciones constitutivas de derechos -que intentan la modificación de un estado jurídico existente- por la otra, en que tienen la particularidad de agotar su cometido en la mera declaración respecto de la existencia de una relación jurídica, de un derecho, de su eficacia, de su modalidad o de su interpretación para un caso concreto, cuando dichos aspectos se encuentran controvertidos, haciendo cesar un estado de incertidumbre respecto de su vigencia y aplicación.

Su finalidad, entonces, es la de procurar certeza jurídica a una relación jurídica cuando esa incertidumbre le es perjudicial, siendo suficiente tal declaración para satisfacer el interés de quien la propone.

Al decir de Guillermo J. Enderle, en su clásica obra "La pretensión meramente declarativa” - Librería Editora Platense, 2da. Edición, La Plata, 2005, P. 23 - esta pretensión “... constituye una de las instituciones del Derecho que, con perfiles nitidamente propios y dimensiones que se proyectan en el campo de operatividad de los modernos estudios procesales, tiende a la consolidación de los aspectos que hacen a la función preventiva de la Jurisdicción, proveyéndose a la declaración de la voluntad de la ley, antes de que se lleven a cabo actos ilegítimos que produzcan consecuencias irreparables".

En el orden federal el art. 322 del Código Procesal Civil y Comercial de la Nación establece: "Podrá deducirse la acción que tienda a obtener una sentencia meramente declarativa para hacer cesar un estado de incertidumbre sobre la existencia, alcance o modalidades de una relación jurídica, siempre que esa falta de certeza pudiera producir un perjuicio o lesión actual al actor y éste no dispusiera de otro medio legal para ponerle término inmediatamente".

Quedan de este modo delineados los tres requisitos esenciales para su procedencia: a)

8 CONVENCION AMERICANA SOBRE DERECHOS HUMANOS Artículo 8. Garantías Judiciales 1. Toda persona tiene derecho a ser oída, con las debidas garantías y dentro de un plazo razonable, por un juez o tribunal competente, independiente e imparcial, establecido con anterioridad por la ley, en la sustanciación de cualquier acusación penal formulada contra ella, o para la determinación de sus derechos y obligaciones de orden civil, laboral, fiscal o de cualquier otro carácter; Artículo 25. Protección Judicial 1. Toda persona tiene derecho a un recurso sencillo y rápido o a cualquier otro recurso efectivo ante los jueces o tribunales competentes, que la ampare contra actos que violen sus derechos fundamentales reconocidos por la Constitución, la ley o la presente Convención, aun cuando tal violación sea cometida por personas que actúen en ejercicio de sus funciones oficiales. Vid norma citada en http:// www.derhuman.jus.gov.ar/pdfs/CONVENCION_AMERICANA_SOBRE_DERECHOS_HUMANOS.pdf.

9 HARO, Ricardo, La Doctrina Judicial de la Corte Suprema de Justicia de la Nación sobre la Acción Declarativa de Inconstitucionalidad, Academia Nacional de Derecho y Ciencias Sociales de Córdoba (República Argentina), www.acaderc.org.ar/doctrina/artículos/artacciondeclarativadeinconstituciona/. 
un estado de incertidumbre jurídica sobre la existencia, alcance o modalidades de una relación jurídica; b) que fuere susceptible de producir al actor un perjuicio o lesión actual y c) que no pudiese ser evitada por otro medio legal.

$\mathrm{Si}$, además, la incertidumbre que se pretende despejar tiene contenido constitucional, entonces estaremos en presencia de una acción declarativa de inconstitucionalidad, conforme se verá seguidamente.

La finalidad declarativa de esta acción, su efecto de cosa juzgada material -en cuanto lo decidido resulta obligatorio para las partes del litigio- y la imposibilidad de ejecución que se deriva de su naturaleza, han sido claramente explicitados en un fallo reciente emanado del Máximo Tribunal de la Nación, en el que se expresó:

"...La pretensión declarativa se satisface con la mera declaración que pone fin a un estado de incertidumbre respecto de una relación jurídica, de modo tal que su efecto es producir cosa juzgada. Como su propósito es la obtención de seguridad jurídica sobre un punto controvertido, no es susceptible de ejecución procesal forzada" 10.

En cuanto a su trámite, debe señalarse que el mismo se encuentra regulado en la segunda parte de la norma ya citada en cuanto prescribe: "El Juez resolverá de oficio y como primera providencia, si corresponde el trámite pretendido por el actor, teniendo en cuenta la naturaleza de la cuestión y la prueba ofrecida", disposición que debe ser completada con lo dispuesto en el artículo precedente en cuanto, al regular el juicio sumario establece que será aplicable el procedimiento establecido en el artículo 498 -juicio sumarísimo- a los procesos de conocimiento de menor contenido económico, o bien "cuando se reclamase contra un acto u omisión de un particular que, en forma actual o inminente lesione, restrinja, altere o amenace con arbitrariedad o ilegalidad manifiesta algún derecho o garantía explícita o implícitamente reconocidos por la Constitución Nacional, un tratado o una ley, siempre que fuere necesaria la reparación urgente del perjuicio o la cesación inmediata de los efectos del acto, y la cuestión, por su naturaleza, no deba sustanciarse por alguno de los procesos establecidos por este Código u otras leyes, que le brinden la tutela inmediata y efectiva a que está destinada esta vía acelerada de protección o en los demás casos previstos por este Código u otras leyes", precisando seguidamente que "si de conformidad con las pretensiones deducidas por el actor no procediere el trámite de juicio sumarísimo, el juez resolverá cuál es la clase de proceso que corresponde".

En definitiva, en función de lo peticionado por el interesado en el escrito de interposición de la demanda declarativa, de conformidad con las pruebas acompañadas, y atendiendo a la urgencia requerida por las circunstancias del caso para reparar la presunta lesión que se denuncia, el juez interviniente deberá resolver, en su primera providencia, el trámite que deberá imprimirse a la pretensión deducida.

\section{2.- La acción declarativa de inconstitucionalidad}

Sobre el origen y la trascendencia de la A.D.I. ha señalado prestigiosa doctrina: "la acción declarativa de inconstitucionalidad es una de las novedosas vías procesales para la actuación de dicho control, y que como en tantas otras loables circunstancias, ha nacido no de la norma legislada, sino del ingenioso desarrollo jurisprudencial de nuestro más alto tribunal, en virtud del ejercicio de un poder constituyente material que le permite, como intérprete final de la Constitución, fijar el sentido y los ámbitos de actuación de las normas supremas"

10 CSJN - "Recurso de Hecho en Asociación Multisectorial del Sur en Defensa del Desarrollo Sustentable c/ comisión de energía atómica" del 26-05-2010, en el voto del Ministro Ricardo Lorenzetti, http://ar.vlex.com/vid/-250970526.

11 HARO, Ricardo, "La Doctrina Judicial...", ya citado, págs. 1/2.. 
En ese contexto, es dable definir la acción declarativa de inconstitucionalidad como un proceso constitucional autónomo y de excepción, de trámite sumario o sumarísimo, como una de las herramientas fundamentales de que disponen los justiciables para ejercer de control y la defensa de sus derechos y garantías constitucionales y salvaguardar la supremacía constitucional, tanto en el orden nacional como en los diferentes órdenes provinciales.

A diferencia de la acción declarativa de certeza, cuyo objeto es despejar una incertidumbre respecto de una cuestión de hecho o de derecho común -si bien puede llevar inserta por vía indirecta una cuestión constitucional- la acción declarativa de inconstitucionalidad tiene por objeto el análisis de la adecuación constitucional de un acto normativo determinado, de alcance general, y su finalidad es la consiguiente declaración de invalidez o inaplicabilidad de la norma irregular.

Su deducción supone, entonces, una relación jurídica integrada por las partes de autos (sujetos), que tienen por finalidad obtener la resolución jurisdiccional de un conflicto (objeto), causado por la existencia de una norma que se reputa inconstitucional (causa); manifestando el accionante su interés jurídico (lesión) en promover la acción, aspecto que guarda una íntima relación con el estado de incertidumbre que debe ser remediado, buscando precaver los efectos de actos en ciernes -a los que se atribuye ilegitimidad- y fijar las relaciones legales que vinculan a las partes en conflicto (fin), por medio de la declaración de inconstitucionalidad de la norma reprochada por transgredir el orden jurídico fundamental.

En el orden federal, la acción declarativa de inconstitucionalidad que tramita ante la Corte Suprema de Justicia de la Nación, a pesar de carecer de regulación positiva, tiene recepción reciente en la jurisprudencia del Máximo Tribunal de la Nación ${ }^{12}$ como vía excepcional de realización de la garantía jurisdiccional de certeza jurídica ${ }^{13}$ cuando se dan los requisitos de su intervención en instancia originaria y en el marco de la acción meramente declarativa regulada en el art. 322 de código adjetivo de la Nación, ya enunciado. Al respecto es oportuno señalar que si bien los ordenamientos provinciales receptan ampliamente la acción declarativa de inconstitucionalidad, en sus respectivas normas fundamentales o en sus códigos adjetivos, en el orden federal la admisión de esta herramienta procesal, como una entidad diferente de la acción meramente declarativa sobre la cual se injerta, ha sido el fruto de una larga evolución doctrinaria y jurisprudencial.

Originariamente, y con miras a resguardar celosamente el principio de división de poderes $^{14}$, el planteamiento de una cuestión constitucional sólo era admitido por la Corte por vía incidental, indirecta o de excepción, quedando excluidas las declaraciones judiciales directas de inconstitucionalidad de las normas o actos de los otros poderes del Estado, cuando su aplicación no se hubiese cuestionado en una controversia entre partes con intereses jurídicos contrapuestos y propios para la dilucidación jurisdiccional ${ }^{15}$, no respondiendo al concepto de "caso" la pretensión ejercida a través de una acción declarativa.

En ese marco jurisprudencial y a pesar de la incorporación de la acción meramente declarativa al Código Procesal Civil y Comercial de la Nación en 1968, mediante la Ley 17.454, durante largo tiempo la Corte rechazó sistemáticamente las cuestiones de inconstitucionalidad que se pretendía encauzar a través de ella, con sustento en que esa

\footnotetext{
12 CSJN - Fallos: 310:142 en "Gomer c/ Provincia de Córdoba", del 03-02-1987.

13 PEYRANO, Jorge W., Cuestiones Procesales Modernas, La Ley, Buenos Aires, 2005, pág. 58.

14 CSJN - Fallos: 242-353 de 1958 en "Hogg...”.

15 CSJN - Fallos: 256:104 de 1963 en "Bco. Hipotecario Nacional c/ Provincia de Córdoba".
} 
vía se encontraba reservada a cuestiones regidas por el derecho común ${ }^{16}$, y en que la acción declarativa no constituía una verdadera "causa judicial" en la doctrina de esa Corte, por lo que ese Tribunal no se hallaba constitucionalmente habilitado para efectuar declaraciones de inconstitucionalidad generales y abstractas ${ }^{17}$.

Argumentó igualmente el Tribunal Cimero que no resultaba un óbice para el sostenimiento de esa doctrina el reconocimiento de la existencia de acciones declarativas de inconstitucionalidad en algunas provincias del Estado federal por cuanto lo allí resuelto quedaba reservado al ámbito jurisdiccional local ${ }^{18}$.

Al decidir de tal modo la Corte ratificaba su posición de que una mera cuestión declarativa resultaba ajena a la instancia extraordinaria, reiterando su doctrina sobre la inexistencia en el orden nacional de la acción declarativa de inconstitucionalidad ${ }^{19}$ y a la imposibilidad de ejercer el control de constitucionalidad fuera de los casos que culminaban con una sentencia de condena ${ }^{20}$.

Recién en 1985, en el fallo dictado en autos "Provincia de Santiago del Estero c/ Estado Nacional y/o Y.P.F." ${ }^{21}$-con antecedente en un voto del Ministro Fayt en el caso "Hidronor c/ Provincia de Neuquén", en sentido concordante con el dictamen del Procurador General de la Nación, en orden a la inexistencia de obstáculos de índole constitucional para que se admita el carácter de "causa" que inviste el ejercicio de las acciones declarativas regladas por el artículo 322 del CPCCN- la Corte reconoció explícitamente la posibilidad de plantear una cuestión constitucional a través de esta acción, persiguiendo una declaración preventiva, que impida poner en vigencia una norma -tributaria, en aquel supuesto- contraria al orden constitucional.

En la causa referida, el Tribunal advirtió que la solicitud de declaración de certeza efectuada no tenía carácter simplemente consultivo ni importaba una indagación meramente especulativa, siendo la acción ejercida un medio plenamente eficaz y suficiente para satisfacer el interés del proponente, antes de que la lesión a los derechos constitucionales de la actora se hubiese configurado, y llegó incluso a reencauzar la acción -originariamente deducida como amparo- en el marco del art. 322 considerado, por entender que puede prescindirse válidamente del nomen juris utilizado por el actor, atendiendo a la real sustancia de la pretensión ejercida, en consideraciones que por su trascendencia merecen ser aquí reproducidas.

Así, el Máximo Tribunal de la Nación admitió expresamente que: "parece evidente que la acción declarativa que, como el amparo, tiene una finalidad preventiva y no requiere la existencia de daño consumado en resguardo de los derechos, es un medio plenamente eficaz y suficiente para satisfacer el interés de la actora que, en las actuales circunstancias, se agota en una mera declaración de certeza".

Subrayó asimismo la Corte, en el referido pronunciamiento, el carácter esencialmente preventivo de este proceso, al decidir: "Que como se advierte, la provincia persigue una declaración preventiva que impida que, en la oportunidad de ponerse en vigencia la ley que dictó su legislatura, el Estado Nacional concrete las medidas anticipadas en los telegramas mencionados anteriormente y que funda en las normas legales citadas. Se está, por consiguiente, frente a una solicitud de declaración de certeza, porque no tiene carácter simplemente consultivo ni importa una indagación meramente especulativa,

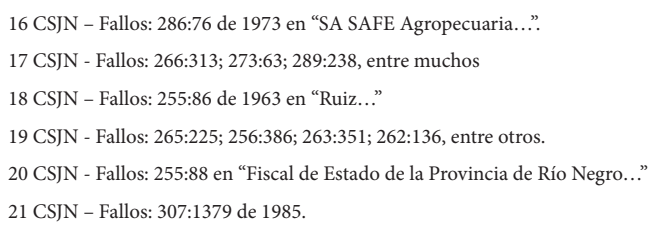


sino que responde a un "caso" y busca precaver los efectos de un acto en ciernes al que se atribuye ilegitimidad y lesión al régimen constitucional federal, y fijar las relaciones legales que vinculan a las partes en conflicto."

Resulta de interés destacar, finalmente, que para encauzar la pretensión ejercida como acción declarativa -originariamente era una acción de amparo ${ }^{22}$ - el Tribunal entendió que en ese supuesto se habían configurado las exigencias requeridas para la existencia de un caso judicial en la Jurisprudencia de la Corte Suprema de Estados Unidos, que cita $^{23}$, en cuanto se cuestionaba una actividad administrativa que tenía concreción bastante y que afectaba un interés legítimo, provocando un grado de afectación suficientemente directo.

Ello así, para que una acción declarativa de inconstitucionalidad resulte admisible ante la jurisdicción constitucional se requiere la existencia de un agravio constitucional actual o inminente, planteado por quien posea un interés legítimo y suficiente, en relación a intereses $o$ asuntos no excluidos expresamente del control judicial, siempre y cuando esta acción sea la única vía posible para que el juez declare la existencia y el alcance de los derechos constitucionales en conflicto, debiendo el interesado alegar y probar la inconstitucionalidad que se denuncia, la que en caso de ser declarada sólo tendrá como efecto su inaplicabilidad al caso concreto.

De este modo, a través del ejercicio de la función jurisdiccional, la magistratura constitucional podrá otorgar certeza a los derechos controvertidos, aún antes de que se produzca lesión alguna y, consecuentemente, garantizar la seguridad jurídica allí donde están en peligro los derechos y garantías constitucionales.

Así lo reconoció nuestro Tribunal Cimero al expresar que: "El pedido de declaración de inconstitucionalidad de una norma importa el ejercicio de una acción directa de inconstitucionalidad, de aquellas que explícitamente la Corte ha admitido como medio idóneo, ya sea bajo la forma del amparo, la acción de mera certeza o el juicio sumario en materia constitucional, para prevenir o impedir las lesiones de derechos de base constitucional'"24. En síntesis, en la acción declarativa de inconstitucionalidad el estado de hecho que configura su sustrato se funda en la duda razonable respecto a la constitucionalidad de la norma de alcance general impugnada por el accionante, una incertidumbre que se proyecta en las relaciones, deberes y derechos de las partes enfrentadas en el litigio, siendo el fin perseguido obtener una resolución judicial por la cual se declare que la norma impugnada resulta violatoria del orden constitucional vigente, conforme al principio de supremacía constitucional ${ }^{25}$, poniendo fin al estado de falta de certeza respecto a la validez de dicha norma en virtud del cual se requirió la intervención del órgano jurisdiccional. Resta señalar sobre el particular que la doctrina nacional considera que la incertidumbre requerida a los fines de pretensión constitucional analizada, que algunos llegan a definir como "un estado de perplejidad", puede verificarse en dos supuestos: en relación a la oscuridad de la norma en sí misma, la que por su falta de claridad conceptual resulta susceptible de generar tal estado de incerteza, o bien respecto de un acto normativo -aún claramente formulado- no ya considerado en sí mismo sino en relación a otros de jerarquía superior, es decir, en cuanto resulta susceptible de contradicción con el bloque constitucional vigente ${ }^{26}$.

\footnotetext{
22 Del mismo modo, en "Edesur..., CSJN Fallos: 320:1093.

23 CS E.E.U.U. Aetna Life Insurance Co. c. Havorth, 300 U.S. 227.

24 CSJN - Fallos: 320:690 de 1997 en "Asociación de Grandes Usuarios de Energía Eléctrica de la República Argentina c/ Provincia de Buenos Aires y otro". 25 T.S.J., Sala Electoral, "La Falda - Departamento Punilla", Auto nº 73 del 13/12/2005; "Murcia", Auto nº 41 del 2/12/2011.

26 TORICELLI, Maximiliano (2005) La acción de inconstitucionalidad en Derecho Procesal Constitucional, coordinador Pablo Luis Manili, Editorial Universidad, Buenos Aires, p. 272..
} 
En consecuencia, cuando lo que se cuestiona es la contradicción de una norma con otra de jerarquía no constitucional, o bien, cuando se hace un planteo de supuesta inconstitucionalidad sin fundamentar suficientemente la existencia de contradicción entre una norma y un principio o un derecho constitucional, la acción no puede ser admitida.

\section{El carácter preventivo de la acción declarativa de inconstitucionalidad}

Tal como ha enfatizado la Corte, en el orden federal la acción declarativa, al igual que el amparo, tiene una finalidad preventiva y no requiere la existencia de un daño consumado en resguardo de los derechos ${ }^{27}$. El planteo oportuno de la cuestión constitucional sigue siendo motivo de debate en la doctrina; ello así toda vez que la exigencia de lesión actual contenida en el art. 322 de la ley adjetiva debe ser considerada en consonancia con la naturaleza preventiva de la acción declarativa.

Al decir de la Corte Suprema de Justicia, la actualidad del perjuicio se deriva de una actividad explícita del poder administrador que importe la manifestación inequívoca de su voluntad de aplicar la norma que se cuestiona en su adecuación constitucional y que se cierne como una amenaza sobre el posible afectado ${ }^{28}$.

Sin embargo, en casos de innegable trascendencia institucional la Corte ha obviado la exigencia de ese requisito admitiendo la acción declarativa y aún declarando la inconstitucionalidad de la norma debatida, pese a la ausencia de actividad de la Administración ${ }^{29}$, doctrina que fuera retomada más recientemente en "Aguas de Formosa S.A.", pronunciamiento en que la Corte transformó la acción de amparo deducida en acción declarativa, haciendo lugar a la medida cautelar solicitada, por el sólo hecho de haberse dictado la ley y sin actividad concreta por parte del Estado provincial demandado ${ }^{30}$.

El Código Procesal Constitucional de Tucumán, al regular expresamente la acción declarativa de inconstitucionalidad, en su artículo 89 prevé que ella puede deducirse con el objeto de "obtener la declaración de inconstitucionalidad total o parcial de una norma legal o disposición normativas con fuerza de ley, provincial o municipal, o de reglamentos $u$ ordenanzas provinciales o municipales, o actos administrativos, para hacer cesar un estado de incertidumbre sobre la constitucionalidad de una relación jurídica, siempre que esta falta de certidumbre pueda producir un perjuicio o lesión al actor y éste no dispusiere de otro medio legal para ponerle término inmediatamente", petición a la que se le imprimirá el trámite sumario fijado en el Código de Procedimiento Civil y Comercial Provincial.

Más adelante, en orden al interés susceptible de ser ejercido, establece en su artículo 90 in fine que "El caso contencioso a que da lugar una acción declarativa de inconstitucionalidad no se limita a las cuestiones de índole económica de interés privado del justiciable, sino que comprende la defensa por parte de cualquier persona o asociación de los intereses públicos que se encuentran protegidos explícita o implícitamente por el orden jurídico nacional y provincial o internacional aplicables en la Provincia”.

En ese marco, no caben dudas que como presupuesto habilitante para la interposición de una A.D.I. se requiere que la norma cuestionada en su constitucionalidad haya sido efectivamente sancionada, pues el sistema de control constitucional argentino sólo está diseñado respecto de normas del ordenamiento jurídico que se encuentren vigentes y

27 CSJN - Fallos: A.G.U.E.E.R.A., ya citado, entre muchos.

28 CSJN - Fallos: 310:142 en “Gomer..., ya citado, y 310:609 en "Newland..., entre otros.

29 Así lo entendió la Corte en los casos "Fayt..." -Fallos: 322:1616-; “Iribarren..." -Fallos 322: 1251- y "Reutemann..." -Fallos 317:1195.

30 Cfr. fallo citado en La Ley 2011-C-250. 
puedan, por ende, generar efectos jurídicos ${ }^{31}$.

El problema se plantea, en cambio, en relación al tiempo en que esta acción debe deducirse: en forma preventiva, es decir antes de la efectiva aplicación de la norma cuestionada respecto del presunto afectado, o cuando su aplicación se cierne sobre el particular como una amenaza actual o inminente, o cuando el mandato legal ha tenido actos de concreción suficiente por parte del Estado administrador, o después de producida la lesión, o en cualquier tiempo.

La primera solución, esto es la deducción de la acción antes de que se produzca la lesión constitucional, es mayoritaria, y responde a la naturaleza de esta acción, conforme ha quedado consagrado por la jurisprudencia federal, en el sentido que, por ser ella esencialmente declarativa y de carácter preventivo, a diferencia del amparo que se perfila como un remedio reparador de la lesión constitucional ya concretada, exige que la tutela judicial sea instada antes de producida la lesión a los derechos constitucionales que se invocan.

Sin embargo, en algunas regulaciones locales se admite que la A.D.I. sea deducida a posteriori, dentro de un plazo acotado previsto en un plazo de treinta a sesenta días de la sanción de la norma o de producida la afectación o lesión constitucional que se denuncia. En otras provincias argentinas se consagra la vía originaria para la defensa de derechos esenciales, sin plazo de caducidad para su interposición y si, por el contrario la acción se ejercita en defensa de derechos de contenido patrimonial, ella sólo podrá deducirse dentro del plazo de caducidad fijado por las leyes adjetivas. Vencido dicho plazo o no concurriendo los requisitos formales o sustanciales fijados por los ordenamientos locales para la admisibilidad y procedencia en instancia originaria, podrán los presuntos afectados acudir a las vías ordinarias, impetrando el control constitucional a través de una acción mere declarativa de exclusivo contenido constitucional o en la que la cuestión constitucional se inserte en la causa principal como defensa o excepción de inconstitucionalidad, con eventual control por vía recursiva del Superior Tribunal provincial.

A modo ilustrativo, corresponde considerar lo dispuesto por el artículo 786 del Código Procesal Civil misionero cuando, al regular la demanda de inconstitucionalidad dispone que la misma "se interpondrá ante el Superior Tribunal de Justicia dentro del plazo de treinta (30) días computados desde que el precepto impugnado afecte concretamente los derechos patrimoniales del actor. Después de vencido ese plazo, se considerará extinguida la competencia originaria del Superior Tribunal sin perjuicio de la facultad del interesado para ocurrir a la jurisdicción ordinaria en defensa de los derechos patrimoniales que estime afectados"32.

Así lo prevén igualmente los ordenamientos adjetivos de Mendoza (art. 233 inc. II C.P.C.), La Rioja (art. 386 C.P.C.) y Tierra del Fuego (art. 316 C.P.C.), que habilitan a deducir la acción dentro de los treinta días de producida la lesión, habiéndose precisado que dicho plazo debe computarse desde la fecha de promulgación de la norma debatida -más allá de que la misma reitere el contenido de una norma anterior ${ }^{33}$ o desde que se haya producido una afectación diferenciada a los intereses del peticionante.

Una solución diferenciada adopta la ley adjetiva de la Provincia de Buenos Aires, en cuanto en su art. 684 dispone que si la lesión que se denuncia afecta derechos patrimoniales, la acción directa ante la Corte provincial deberá deducirse dentro de los treinta días de producida la lesión; transcurrido ese plazo, el interesado deberá plantear la

31 CSJN - Fallos: 210:855, entre varios.

32 Disposiciones de similar tenor se encuentran en los C.P.C. de BUENOS AIRES, SALTA y SAN LUIS, conforme se explicitará luego, al tiempo de considerar el plazo de interposición de la A.D.I.

33 Cfr. TORICELLI, Maximiliano, op. cit., pág 315/316, en comentario a jurisprudencia de la Corte Suprema de Mendoza, que cita. 
cuestión constitucional por vía ordinaria -pudiendo llegar ante la máxima instancia provincial por vía de recurso-; en cambio, si lo que se denuncia es la afectación de derechos personalísimos o cuando se cuestionan normas de carácter institucional, o cuando la acción se deduce en forma preventiva, es decir cuando la norma no ha sido aún aplicada respecto del interesado, deberá interponerse sin plazo -art. 685 C.P.C.--

Por último, es dable destacar que el Código Procesal Constitucional de Tucumán ya evocado establece, sobre el punto, en su artículo 90, inciso $1^{\circ}$ que "La demanda debe interponerse dentro del plazo de sesenta (60) días corridos a contar desde la publicación oficial de la norma cuestionada, la notificación o conocimiento del acto administrativo. La caducidad del plazo no impide la articulación de la cuestión constitucional por vía de excepción, si en atención a las circunstancias del caso, correspondiere."

En Córdoba, el ejercicio del control de constitucionalidad opera a través de ese doble sistema, habiendo sido consagrado el control concentrado, por vía originaria, en la Carta Magna provincial ya desde 1923, en su artículo 132 inciso $1^{1034}$, mediante el ejercicio de la acción autónoma de inconstitucionalidad ante el Tribunal Superior de Justicia de la Provincia, resultando, entonces, Córdoba la primera provincia argentina en reconocer constitucionalmente esta potestad de la máxima instancia jurisdiccional local como garante de la supremacía constitucional y del orden jurídico ${ }^{35}$.

El texto originario difería ligeramente del actual, en cuanto disponía: "Art. 132- El Tribunal Superior tiene las siguientes atribuciones, sin perjuicio de las que la acuerdan los artículos 133, 137 y 156: 1o Ejercer la jurisdicción originaria y de apelación para conocer y resolver la constitucionalidad o inconstitucionalidad de leyes, decretos, resoluciones, ordenanzas y reglamentos que estatuyen sobre materia regida por esta Constitución y se discuta, en caso concreto, por parte interesada. $2^{\circ} \ldots .$.

Resultaba, dicha disposición, absolutamente innovadora toda vez que hasta ese momento el Tribunal Superior y las Salas que lo conformaban no ejercían jurisdicción originaria, salvo en lo atinente a conflictos de competencia entre tribunales jurisdiccionales, recusación de sus Vocales o de jueces inferiores y causas sobre responsabilidad civil de magistrados y jueces de paz ${ }^{36}$.

A partir de la reforma constitucional de 1987, dicha acción ha sido atribuida en forma exclusiva y excluyente al Tribunal Superior de Justicia por el artículo 165, inciso 1, apartado "a" de la Constitución Provincial, en calidad de máximo intérprete de la carta magna provincial, norma que habilita el control directo de constitucionalidad en "vía originaria y exclusivamente, en pleno", a través de las "...acciones declarativas de inconstitucionalidad de las leyes, decretos, reglamentos, resoluciones, Cartas Orgánicas y ordenanzas, que estatuyan sobre materia regida por esta Constitución, y se controviertan en caso concreto por parte interesada... ${ }^{\prime \prime 37}$.

Dicha competencia exclusiva es igualmente ratificada por el art. 11 inciso 1 apartado "a" de la Ley Orgánica del Poder Judicial N 8435, que reproduce casi textualmente la norma constitucional.

A partir de la sanción del nuevo Código Procesal Civil y Comercial de la Provincia, Ley № 8465 -en adelante C.P.C.- vigente desde el 23 de junio de 1996, luego de un breve

\footnotetext{
34 Según proyecto despachado por la Comisión de Organización Constitucional, considerado en la Sesión de la Convención Constituyente del 17-09-1923, junto con una moción similar introducida por el convencional Julio Rodríguez de la Torre, luego reconsiderado el 06-10-23, día en que se aprobó su texto definitivo.

35 Le siguieron las Constituciones de Entre Ríos en 1933, Neuquén, Chaco, Río Negro y Formosa en 1957, en ese orden; Misiones en 1958, La Pampa en 1960 y, años más tarde, las demás.

36 Cfr. TORRES, Arturo (1943): La Constitución de Córdoba - Estudio Histórico, Editorial Ideas, Buenos Aires pág. 238 y ss.

37 T.S.J. Cba., Sala Contencioso Administrativa, "Tassile, Carlos Alberto y otros c/ Municipalidad de Río Cuarto - Acción Declarativa de Inconstitucionalidad", Auto Interlocutorio n 533 del 05-12-1996, entre muchos.
} 
período de transición en que se mantiene el trámite de juicio ordinario ${ }^{38}$, y entendiendo el Tribunal Superior de Justicia que la acción autónoma de inconstitucionalidad es una especie de acción declarativa, se le imprime el trámite de juicio abreviado previsto en el art. 418 inc. $3^{\circ}$ ib., con la particularidad de contar con una etapa previa de admisibilidad formal, propia del carácter excepcional de esta vía de control, en la que el tribunal procede a analizar si la acción deducida cumplimenta los recaudos formales necesarios para ser admitida, los cuales se fijan sobre la base de lo preceptuado por la Constitución Provincial.

Ellos son: a) que exista instancia de parte interesada; b) que el acto impugnado sea una norma que regule conductas en forma general, abstracta e impersonal, que se encuentre vigente, cuando la oscuridad de su texto genere la sospecha de su inconstitucionalidad; o cuando pese a la contundencia de su redacción, se susciten dudas sobre su adecuación a la Carta Magna", en cuanto su contenido "estatuya sobre materia regida por esta constitución" y que tal regulación se postule como lesiva del ordenamiento constitucional local ${ }^{40}$; c) que haya "caso" concreto, es decir un conflicto de intereses entre partes adversas y d) que la norma regule sobre materia regida por la Constitución de Córdoba en forma originaria o mediante una reiteración de lo regulado por la Constitución Nacional $^{41}$.

Ahora bien, cuando la declaración de inconstitucionalidad por vía directa no se presenta como la única vía -ni aún la más idónea- que permita habilitar el control judicial de constitucionalidad de la norma impugnada, la acción intentada deviene inadmisible ${ }^{42}$.

Por lo demás, sólo cuando el agravio surge de manera directa e inmediata de una norma local, de carácter general, $y$ antes de consumarse o generarse actos aplicativos de aquella, puede el potencial afectado, de concurrir los demás requisitos legales y jurisprudenciales de admisibilidad, proponer la acción autónoma de puro control de constitucionalidad; de lo contrario, es decir cuando la lesión constitucional ya se ha configurado la acción declarativa deviene inadmisible, debiendo el interesado acudir a las vías ordinarias para perseguir la reparación del daño sufrido.

El distingo entre la protección constitucional "preventiva" y "represiva", configura una doctrina constante del Tribunal Superior de Justicia ${ }^{43}$, a través de la cual se ha puesto de manifiesto que nuestro régimen procesal conoce las dos vías clásicas que aseguran la efectiva aplicación del texto constitucional: la directa, por acción o demanda de inconstitucionalidad y la indirecta o incidental.

En la vía incidental, la cuestión constitucional injertada en una causa ordinaria planteada ante cualquier fuero, por vía de demanda, defensa, excepción o incidencia, puede ser juzgada por cualquier juez provincial, con conocimiento en instancia última, por vía de

38 T.S.J. Cba. "Murias de Pizarro, María Cristina c/ Provincia de Córdoba y otra - Acción de Inconstitucionalidad"- Auto Interlocutorio n 369 del 26-081996.

39 Cfr. TORICELLI, Maximiliano, La Acción de Inconstitucionalidad en Argentina. Un Camino Con Luces,en: profesorjimenez.com.ar/cdroms/7jornadas derproceconst21220803/exposiciones/Toricelli.pdf.

40 T.S.J. Cba. "Barrutia, Fernando Santiago y otros c/ Provincia de Córdoba - Acción de Inconstitucionalidad", Auto n 2 del 12-02-2001; "Milanese, Eduardo Alberto c/ Honorable Tribunal de Disciplina de Abogados de la Provincia de Córdoba - Acción Autónoma de Inconstitucionalidad”, Auto n 67 del 16-122008 , entre otros.

41 T.S.J. Cba. "Sánchez, Héctor c/ Provincia de Córdoba y otra - Acción de Inconstitucionalidad”, Auto Interlocutorio n 287 del 03-07-1996; “Castellano, Aníbal c/ Provincia de Córdoba y otro - Acción de Inconstitucionalidad", Auto Interlocutorio no 388 del 29-08-1996; "Caradaghian, Arturo S. y otros c/ Municipalidad de Córdoba y otro - Acción de Inconstitucionalidad", Auto Interlocutorio n 53 del 21-05-1998; "Imberti, Alberto c/ Municipalidad de Río Cuarto - Acción de Inconstitucionalidad", Auto Interlocutorio no 96 del 18-09-1998; "Cet S.A. c/ Municipalidad de Río Cuarto - Acción de Inconstitucionalidad", Auto no 33 del 07-09-2009, entre otros.

42 T.S.J. Cba. "Loveli S.A. - Acción de Inconstitucionalidad", Auto nº 14 del 19-04-2004, entre muchos.

43 T.S.J. Cba. "Banco Social de Córdoba c/ Municipalidad de San Francisco", Sentencia nº 50 del 05-08-83, en La Ley Córdoba, 1984, pág. 239 y ss.; "Manavella Oscar Juan c/ Provincia de Córdoba y otra - Acción Declarativa de Inconstitucionalidad", Auto Interlocutorio n 536 del 12-12-96; "Martínez, José Francisco c/ Caja de Jubilaciones, Pensiones y Retiros de la Provincia de Córdoba - Acción Declarativa de Inconstitucionalidad", Auto Interlocutorio $\mathrm{n}^{\circ} 20$ del 04-03-97, entre muchos. 
recurso extraordinario de casación o de inconstitucionalidad, del Tribunal Superior de la Provincia, con intervención de una de sus Salas, según la materia.

En la vía directa, en cambio, y por mandato constitucional, el Alto Cuerpo conoce del caso constitucional en forma originaria y en pleno, con competencia exclusiva y excluyente, en función de lo normado en el art. 165, inc. 1, ap. "a" de la Carta Magna Provincial, ya reproducido.

Así, mientras la vía directa trae a consideración del juez la cuestión constitucional pura, esto es, desprovista de toda otra cuestión litigiosa, la vía incidental permite llevarla "injertada" dentro de una controversia principal a la cual accede de forma incidental y a la cual condiciona como cuestión prejudicial.

Una y otra vía responden a situaciones y necesidades muy distintas, y en esa diferencia reside su naturaleza peculiar; pero debe quedar bien en claro que, en ambos supuestos, debe tratarse de un conflicto de intereses entre partes adversas, en el que se encuentran en conflicto derechos y/o garantías de raigambre constitucional.

En la vía incidental, el derecho del actor ha sido afectado por una violación ya consumada, y el proceso sirve para restablecer la vigencia y efectividad del orden jurídico alterado. La causa de pedir es un perjuicio concreto sufrido por aquel a quien se concede la acción, para que obtenga su satisfacción mediante la condena del infractor. Se trata, respectivamente, de una acción y una sentencia de condena, y esta última sirve de título hábil para perseguir la ejecución compulsiva del demandado.

La acción originaria, en cambio -explica el Tribunal- supone, no una violación ya consumada, sino una amenaza, una relación jurídica o un derecho en trance de verse lesionados, respecto de los cuales se avizora una afectación derivada de la norma impugnada y que debería producirse según el curso natural de las cosas, lo que implica la necesaria existencia de una actividad explícita por parte de la Administración orientada a hacer valer la norma que se cuestiona, respecto del presunto afectado ${ }^{44}$.

Ello así, en razón de que por los efectos meramente declarativos de la resolución que pone fin a la acción, no constitutivos de derechos, ésta resulta ineficaz para restablecer las consecuencias gravosas de un perjuicio o gravamen ya producido ${ }^{45}$.

Desde otro costado, y por imperio de la doctrina de los actos propios, la acción declarativa tampoco resulta admisible cuando a través de ella se persigue la inaplicabilidad de una ley cuya vigencia y aceptación por los presuntos afectados data de un largo tiempo y en virtud de ello, el supuesto daño que se invoca ya se ha consumado.

Sin embargo, la jurisprudencia del Tribunal Superior de Justicia reseñada precedentemente, en orden al necesario carácter preventivo de la acción declarativa de inconstitucionalidad ha sido resistida por algunos magistrados inferiores quienes integrando ese Tribunal en sustitución de algunos de sus miembros naturales -o de todos, en algunos casos- en aplicación del art. 15 primer supuesto de la Ley Orgánica del Poder Judicial, han tenido ocasión de expresar su disenso, siempre en voto minoritario.

Así, con motivo de una acción de inconstitucionalidad en la que se debatían derechos previsionales y que el Tribunal, por mayoría, declaró inadmisible por entender que la lesión constitucional denunciada ya se había configurado, en su disidencia, la señora vocal sustituto doctora Nora Garzon de Bello consideró acreditados los extremos exigidos en el art. 165 inc. 1, ap. "a" de la Constitución Provincial para su viabilidad.

Por lo singular del planteo efectuado en orden al requisito bajo examen y por el valor histórico de los datos que apoyan el razonamiento formulado, resulta útil transcribir textualmente parte del voto comentado: 
“...El primero -caso concreto-, entendido como causa judicial concreta, real y actual, no necesariamente como juicio contradictorio, en el que resulta "indiferente" que la acción que se inicie, invocándose la lesión a alguno de los derechos que reconoce, lo sea en forma "preventiva" o "una vez configurada la lesión". Lo antedicho, en función de lo que se desprende de la lectura de los Diarios de Sesiones de la H. Convención Provincial Constituyente de 1987. En efecto, frente a la moción presentada por el Convencional Sr. Gentile en el sentido de que se suprimiera este requisito, en razón de entender que la procedencia de la acción no podía limitarse a los supuestos donde la norma tachada de inconstitucional hubiera sido aplicada, criterio adoptado por la jurisprudencia en ese momento vigente (T.I, págs. 868 y sgtes.), la misma no fue aprobada, teniéndose por tal el texto del art. 132 inc. $1^{\circ}$ de la Constitución Provincial de 1923 (T.I, págs. 874/875 y T.Il, pág. 1177). Este aspecto tampoco fue modificado tras la moción de reconsideración (T.II, págs. 1957 y 1963), señalando solamente el Convencional Sr. Cafferata Nores, en relación a los efectos de la sentencia que en tal procedimiento se dicte, que "debe quedar absolutamente en claro que el fallo que se obtenga como resultado de esta acción, jamás puede interpretarse como una derogación de la ley, ordenanza o disposición legal contra la cual se haya intentado esta acción, ni tampoco que tenga efectos 'erga omnes', es decir fuera del caso concreto". Por su parte, la lectura del Diario de Sesiones de la H. Convención Reformadora de la Constitución Provincial de 1923 evidencia que, en oportunidad de introducirse esta competencia y ante una pregunta concreta del Convencional Sr. Rovelli, el Convencional Sr. Rodríguez de la Torre manifestó que correspondía al Tribunal Superior conocer y resolver en forma "originaria" acerca de la constitucionalidad de las normas y que "para ello no es necesario que se 'aplique' o se ponga en ejecución la ley contraria a la Constitución, bastará que ella se prolongue, para que desde luego pueda, por esta acción pedirse que sea abrogada..." (T.Il, pág. 1976)"*46.

Tras el análisis de los restantes requisitos enunciados, concluyó la Magistrada en que no existiendo plazo de caducidad para la iniciación de la acción y no quedando su admisibilidad condicionada a la inexistencia de otros medios impugnativos idóneos, la misma no puede limitarse en base a requisitos que no surgen del texto constitucional, ni de ley alguna dictada en su consecuencia, dado que tanto la elección del "medio" empleado para obtener el control de constitucionalidad (directo o indirecto), como el de la "oportunidad" para hacerlo valer (preventivo o una vez configurada la lesión) pertenecen en forma exclusiva a la parte actora ${ }^{47}$.

En igual sentido, se expresaron otros Vocales de Cámaras Civiles de Apelaciones, negando el carácter subsidiario de esta acción y su naturaleza preventiva. Afirmaron, sobre dichos aspectos, que del texto del art. 165, inciso 1 apartado "a" de la Carta Magna local surge claramente que el constituyente no califica a la acción declarativa de inconstitucionalidad de "preventiva" o "reparativa o represiva", en cuanto al tiempo en que se produjo la lesión anticonstitucional presuntamente ocasionada por la norma general que cuestiona el interesado en caso concreto, sino que regula una acción "declarativa de inconstitucionalidad", sin aditamento alguno, en orden a la posible violación a la norma constitucional local que se vaya a producir en el futuro, cuando se aplique a un caso concreto o cuando haya amenaza de que ello ocurra, con un objetivo preventivo o bien cuando la supuesta violación ya esté consumada.

En principio -estimaron- los límites estriban en la materia constitucional local, que exista caso concreto y proposición por parte interesada, a lo que agregaron que, tratándose

46 T.S.J. Cba. "Torres Schang, María Margarita c/ Provincia de Córdoba - Acción Declarativa de Inconstitucionalidad", Auto Interlocutorio nº 76 del $03-$ 04-1997.

47 ver igualmente "Cámara Empresarial..." A. nº 22 del 24-06-2002, ya citado, entre otros. 
de valladares al acceso jurisdiccional, ellos deben ser interpretados en sentido estricto, esto es con apego a la letra de la ley, pues rige en la materia el principio in dubio pro accione, de conformidad con lo dispuesto por el artículo 49 de la Constitución Provincial y el artículo 8.1. de la Convención Americana sobre Derechos Humanos "Pacto de San José de Costa Rica".

En cuanto al trámite, han observado que, a diferencia de la acción de amparo que es siempre "excepcional" y se ventila en juicio sumarísimo, la acción declarativa de inconstitucionalidad, como vía excepcional cuyo objeto es declarar la "certeza" de constitucionalidad en lo que es controvertido, requiere de un juicio cognoscitivo que puede ser abreviado o amplio, según que la lesión del derecho o garantía constitucionales se haya producido o no, para resolver en definitiva su constitucionalidad con grado de certeza, a los fines de mantener vigente la observancia del principio de supremacía constitucional, por constituir el orden público máximo, al cual se deben sujetar los poderes constituidos, sin que ello pueda ser objeto de una interpretación "excepcional" o "restringida", que deniegue ab initio dicho control.

Con sustento en las premisas así esgrimidas, concluyeron en que puede promoverse la pretensión declarativa de certeza, no sólo cuando el "daño" o "lesión" que se procura evitar no se ha producido -con carácter preventivo-, sino, y con mayor razón, cuando éste ya se ha producido, disipando toda duda al respecto ${ }^{48}$.

Finalmente, cabe considerar la interpretación del art. 413 del C.P.C. efectuada en una sentencia del T.S.J. de Córdoba, integrado por conjueces, con cita de doctrina en igual sentido ${ }^{49}$, en orden a que dicha norma distingue el "perjuicio" que ocasiona el "estado de incertidumbre" -el cual puede ser actual- de la "lesión" que se procura evitar -que puede ser actual o potencial- lo que no deja duda alguna cuando al final de su texto dice "aun sin lesión actual" y que, además, al guardar silencio sobre el carácter subsidiario de la pretensión declarativa de certeza, la norma parece inclinarse por una tesis amplia, que posibilita la proposición de la pretensión mencionada, aunque el actor pudiera entablar una pretensión de condena ${ }^{50}$.

Sobre el tópico ha precisado, luego, el Tribunal que el momento en que se concreta la lesión o violación constitucional que se denuncia no debe identificarse con la entrada en vigencia de la norma a partir de la fecha de su publicación en el Boletín Oficial, es decir cuando la norma comienza a regir, sino que la expresión "lesión efectiva" debe asimilarse al instante en que el perjuicio ya se ha concretado, es decir cuando la disposición ha tenido aplicación práctica y efectiva y el supuesto perjuicio ya se ha consumado con relación al particular o destinatario de la norma legal ${ }^{51}$.

\section{Reflexiones finales}

A modo de síntesis y propiciando una solución de final abierto que merece ser repensada por los jueces que ejercen el contralor constitucional y a la luz del análisis preceden-

\footnotetext{
48 Cfr. Disidencia del Dr. Alfredo Eduardo Mooney, en Auto Interlocutorio n ${ }^{\circ} 118$ del 29-04-1997 in re "Ortiz, Carlos Alberto c/ Provincia de Córdoba Acción declarativa de Inconstitucionalidad"; Auto Interlocutorio n 272 del 15-08-1997 en "Fernandez, Raúl E. y otros c/ Provincia de Córdoba - Acción de inconstitucionalidad" y voto de los Dres. Raúl Fernandez y Silvana Chiapero en Auto n 3 del 26-02-2004 en "Asociación de Magistrados y Funcionarios Judiciales de Córdoba y otros - Acción de Inconstitucionalidad".

49 PERraCHIONE, Mario C., La Pretensión Declarativa de Certeza en el Nuevo Código Procesal Civil (ley 8465), Foro de Córdoba, Año VII, Tomo 33, 1996, pág. 91/94.

50 T.S.J. Cba. "Fernandez, Raúl E. y otros c/ Provincia de Córdoba - Acción de Inconstitucionalidad", Sentencia nº 9 del 19-12-2000, tribunal integrado por los señores Vocales de Cámara doctores Ricardo Jesús Sahab, Víctor Armando Rolón Lembeye, Humberto Sánchez Gavier, Jorge Miguel Flores, Alfredo Eduardo Mooney, Mario Sarsfield Novillo y Ángel Antonio Gutiez -por apartamiento de sus miembros naturales-.

51 T.S.J. Cba. "Hoyts General Cinema de Argentina S.A. c/ Municipalidad de Córdoba - Acción Declarativa de Inconstitucionalidad”, Auto n 48 del $02-$ 10-2009.
} 
temente efectuado, es dable señalar que tanto a nivel federal, como en la Provincia de Córdoba, y en la mayoría de las provincias argentinas, la jurisdicción extraordinaria en vía originaria se habilita exclusivamente en forma preventiva, en las hipótesis en que se invoque una "amenaza" fundada de sufrir una lesión a los derechos o garantías, individuales o colectivos, de naturaleza constitucional, derivada de la eventual aplicación de una norma positiva respecto del afectado, cuando el presunto gravamen constitucional aún no se ha configurado.

Ello responde esencialmente a su naturaleza declarativa, así como a la regulación de la acción meramente declarativa contenida en el Código de Procedimiento Civil y Comercial de la Nación y a su función de lograr certeza jurídica despejando una incertidumbre que, en el caso concreto, tiene contenido constitucional.

Por otro lado y sin perjuicio de sostener el carácter preventivo de la A.D.I., un sector de la doctrina estima que, no obstante ello, la acción debería ser admitida sin atender a la fecha de sanción de la norma pretendidamente inconstitucional ni a su aplicación anterior en un supuesto diferente, cuando frente a la amenaza a los derechos constitucionales del recla- mante ella resulte la vía más hábil para impedir la consumación de ese daño a su respecto ${ }^{52}$.

En tal sentido, resulta pertinente traer a colación las reflexiones del Dr. Juan C. Hitters, como Ministro de la Suprema Corte de Justicia de Buenos Aires, cuando señalaba que:

"...si limitamos este instituto a la función exclusivamente preventiva y declarativa, le restamos eficiencia y le quitamos al litigante un importante armamento para atacar uno de los vicios más graves, como lo es sin hesitación, el de inconstitucionalidad"53.

Habrá que seguir entonces atentamente la evolución jurisprudencial de este instituto procesal en orden al tiempo de su ejercicio y a los efectos de la resolución a dictar.-

\section{BIBLIOGRAFÍA}

- BIDART CAMPOS (1972): Germán, Manual de Derecho Constitucional Argentino, Ediar, Buenos Aires.

- HARO, Ricardo: La Doctrina Judicial de la Corte Suprema de Justicia de la Nación sobre la Acción Declarativa de Inconstitucionalidad, Academia Nacional de Derecho y Ciencias Sociales de Córdoba (República Argentina), www.acaderc.org.ar/doctrina/artículos/ artacciondeclarativadeinconstituciona/

- PEYRANO, Jorge (2005): Cuestiones Procesales Modernas, La Ley, Buenos Aires.

- PUIGDELLIBOL, María Soledad (2009): La acción declarativa de inconstitucionalidad en la Provincia de Córdoba. El requisito de caso concreto y el carácter preventivo de la acción. Ponencia presentada en el XXV Congreso Nacional de Derecho Procesal 2009, en: www.procesal2009bsas.com.ar/pdfs/...declarativa/Puigdellibol.pdf

- TORICELLI, Maximiliano (2005) La acción de inconstitucionalidad en Derecho Procesal Constitucional, coordinador Pablo Luis Manili, Editorial Universidad, Buenos Aires.

- TORRES, Arturo (1943): La Constitución de Córdoba - Estudio Histórico, Editorial Ideas, Buenos Aires.

52 PUIGDELLIBOL, María Soledad (2009): La acción declarativa de inconstitucionalidad en la Provincia de Córdoba. El requisito de caso concreto y el carácter preventivo de la acción. Ponencia presentada en el XXV Congreso Nacional de Derecho Procesal 2009, en: www.procesal2009bsas.com.ar/pdfs/... declarativa/Puigdellibol.pdf.

53 S.C. Buenos Aires, in re "Clínica y Maternidad Los Hornos S.R.L." fdel 5.3.96, L.L. 1996-D, pág. 237, citado en “Asociación de Magistrados..." Auto n 3 del 26-02-2004, ya referido, en el voto de la minorí. 